\title{
Contents
}

\section{Year in Review 2010}

137 Year in review: health protection in NSW, 2010 Highlights health protection activities undertaken in NSW lead by the Centre in 2010 and includes the annual review of notifications of communicable diseases in NSW.

Centre for Health Protection, NSW Department of Health

149 Compliance with sharps waste standards by a sample of Sydney acupuncture premises

Describes a survey of a random sample of acupuncturists in the City of Sydney local government area to examine how sharps waste is disposed.

Louise Blundell, Toni Cains, Kelly-Anne Ressler and Mark J. Ferson

154 Increased presentations to emergency departments for asthma associated with rye grass pollen season in inland NSW

Data from the NSW Department of Health centralised Emergency Department Data Collection was used to assess the frequency and geographical range of unusually large daily counts of asthma presentations in regional NSW.

Timothy J. Hayden and David J. Muscatello

\section{Bug Breakfast in the Bulletin}

159 Respiratory syncytial virus

Benjamin G. Polkinghorne, Craig M. Mellis and Alison M. Kesson

\section{Factsheet}

\section{Hendra virus}

\section{Communicable Diseases Report, NSW}

162 May and June 2011

\section{NSW PUBLIC HEALTH BULLETIN}

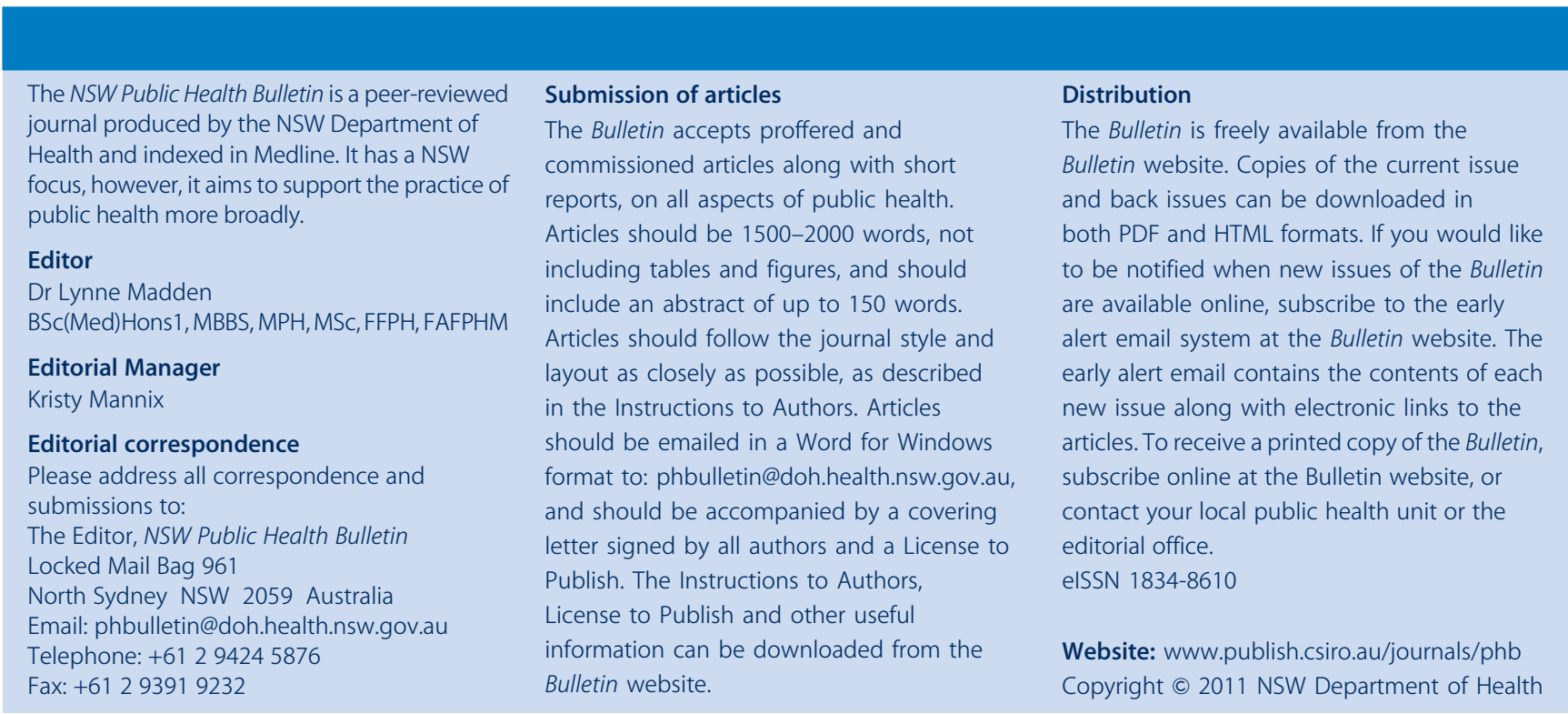

